Majority of patients were treated with combination therapy of pegylated interferon $\alpha 2 \mathrm{a}$ and ribavarin whilst a small proportion (28) have received (triple therapy) protease inhibitors. The total number of patients who achieved sustained virologic response (SVR) at the end of treatment were 264 (60.41\%). 196 (74.42\%) of those were genotype 3a, 57 (21.60\%) were genotype $1 \mathrm{a} / 1 \mathrm{~b}$ and $11(4.17 \%)$ were genotype $2 \mathrm{~b} / 2 \mathrm{a} .43(9.84 \%)$ were considered non-responders. $49(11.21 \%)$ patients were unable to complete treatment due to critical physical or mental illness with 12 of those $(24.50 \%)$ have achieved SVR. Patients' feedback for this nurse-led service has been very positive.

Conclusion Specialist nurse-led and clinicians supported hepatitis $\mathrm{C}$ service has delivered a high quality of care. Our dedicated specialist nurses working closely with clinicians have achieved high successful treatment rates in such a large cohort of patients. Disclosure of Interest None Declared.

\section{PTU-121 LLT1 IS UPREGULATED IN HEPATOCELLULAR CARCINOMA AND INHIBITS NK CELL CYTOTOXICITY}

N Kumar*, A Mroz, M Aletrari, R Goldin, M Purbhoo. Imperial College London, London, UK

\subsection{6/gutjnl-2014-307263.195}

Introduction Liver cancer is on the rise and prognosis is poor partly due to late diagnosis and a lack of systemic chemotherapy. Identification of novel markers allowing early diagnosis of hepatocellular carcinoma (HCC) and to act as targets for immunotherapies is essential to kerb rising mortality. Lectin-like transcript 1(LLT1) interacts with CD161, ${ }^{1}$ a receptor expressed on almost all NK cells. For the first time, we investigate the expression of LLT1 in the liver and HCC, both in vivo and in vitro, and determine the effect of LLT1 on NK cell function.

Methods LLT1 expression in vivo was determined by immunohistochemistry comparing 10 HCC specimens (resections and biopsies) to 15 normal liver controls. In vitro expression was demonstrated using flow cytometry to review HCC cell lines (Huh7, HepG2). Peripheral blood mononuclear cells (PBMCs), including NK cells, from healthy donors were incubated with target cells expressing different levels of LLT1:Huh7 cells, Huh7 cells expressing increased levels of LLT1(achieved by transfection), and Jurkat cells lacking LLT1. The effect of these incubations on $\mathrm{CD} 161^{+}$and CD161-NK cell cytotoxicity was assessed by measuring CD107a expression using flow cytometry. This assay was performed in triplicate using 2 different donors on 3 separate occasions. Statistical analysis of variance (ANOVA) was performed to assess differences in NK cell cytotoxicity between each incubation condition.

Results Hepatocytes in normal and cirrhotic liver do not express LLT1. However, LLT1 is extensively upregulated in HCC in vivo with strong, diffuse staining in 9 out of 10 cases, and more focal staining seen in the remaining case. LLT1 is expressed in vitro on HCC cell lines (Huh7 and HepG2). CD161 ${ }^{+} \mathrm{NK}$ cells show reduced cytotoxicity, compared to CD161-NK cells, when incubated with Huh7 cells expressing LLT1. Incubation with Huh7 cells correlates with significantly reduced activity by CD161 ${ }^{+} \mathrm{NK}$ cells $(\mathrm{p} \leq 0.001)$ when compared to $\mathrm{CD} 161^{+} \mathrm{NK}$ cell activity against non-LLT1 expressing Jurkat cells. $\mathrm{CD} 161^{+} \mathrm{NK}$ cell cytotoxicity is further reduced when incubated with Huh7 cells expressing increased LLT1 levels (as achieved by transfection; $\mathrm{p} \leq 0.05$ when compared to $\mathrm{CD} 161^{+} \mathrm{NK}$ cell activity when incubated with non-transfected Huh7 cells). In contrast, the activity of $\mathrm{CD}_{161}{ }^{+}$and CD161-NK cells is not significantly different when the target cell does not express LLT1(Jurkat cell).

Conclusion We demonstrate for the first time that LLT1 is not expressed by normal liver tissue, but upregulated in HCC. LLT1 inhibits NK cell cytotoxicity, representing a possible mechanism for HCC to evade the immune response to cancer. Therefore, not only may LLT1 be used as a diagnostic marker for HCC, it represents a novel immunotherapy target.

\section{REFERENCE}

1 Aldemir et al. Cutting edge: LLT1 is a ligand for the CD161 receptor. J immunol 2005:7791

Disclosure of Interest None Declared.

\section{PTU-122 A GMP TREG EXPANSION PROTOCOL RESTORES TREG SUPPRESSOR FUNCTION IN END-STAGE LIVER DISEASE; IMPLICATIONS FOR ADOPTIVE TRANSFER THERAPY}

N Safinia*, T Vaikunthanathan, H Fraser, C Scotta, R Lechler, G Lombardi. MRC Centre for Transplantation, King's College London, London, UK

\subsection{6/gutjnl-2014-307263.196}

Introduction Long-term survival in liver transplant recipients remains suboptimal because of the morbidity and mortality associated with the long-term use of immunosuppression (IS). However, IS weaning early post liver transplantation (LT) has largely been unsuccessful, supporting the need for active tolerance induction strategies. $\mathrm{CD} 4{ }^{+} \mathrm{CD} 25^{+} \mathrm{FOXP} 3+$ (Tregs) play an important role in immunoregulation and have been shown in animal models to promote transplantation tolerance. Phase I trials in bone marrow transplantation have shown that ex vivo expanded Tregs have an excellent safety profile, which is encouraging for the broader application of these cells. The clinical trial, ThRIL, soon to be initiated at King's College London, aims to investigate the therapeutic potential of Tregs in the setting of LT.

We have devised a GMP compatible protocol that ensures the successful isolation and expansion of a functional and stable human Treg population in preparation for this trial.

Methods Tregs were isolated from $150 \mathrm{ml}$ of blood from patients with end-stage liver disease by a CliniMACS-based GMP isolation technique and expanded using anti-CD3/CD28 beads, IL-2 and rapamycin.

Results A 580-fold expansion of pure Tregs was achieved (97.4\% $\mathrm{CD}^{+} \mathrm{CD}^{2} 5^{+}$and $0.008 \% \mathrm{CD}^{+}$cells) and the cells maintained FoxP3 expression $\left(99.6 \%\right.$ of the $\mathrm{CD} 4{ }^{+} \mathrm{CD} 25^{+}$cells express FoxP3). The populations of Tregs obtained were also stable and did not convert to Th17 cells when cultured in the presence of pro-inflammatory stimuli.

This protocol further proved to be ideal for the expansion of Tregs from patients with liver disease in view of restoring the Tregs' suppressive function (1:1 ratio - expanded Tregs 91.1\% vs. freshly isolated Tregs $28.6 \%$ suppression, $1: 10$ ratio $-80.7 \%$ vs. $20.8 \%$ respectively). Based on these findings, we subsequently conducted an in-depth phenotypic characterisation of freshly isolated Tregs in order to delineate a population responsible for the apparent lack of suppressive function. An investigation into the possible mechanisms is currently ongoing.

Conclusion The feasibility of Treg based therapy is now widely accepted, provided that tailor-made clinical grade procedures for isolation and ex-vivo cell handling are available. Our rapamycin-based protocol is ideal in this setting as it not only satisfies the rigours of GMP manufacturing standards, but also 
derives a population of Tregs that is stable and functionally superior compared to freshly isolated Tregs.

Disclosure of Interest

None Declared.

\section{PTU-123 USE OF RITUXIMAB IN RESISTANT AUTOIMMUNE HEPATITIS - BIRMINGHAM EXPERIENCE}

${ }^{1,2} \mathrm{~N}$ Gautam*, ${ }^{1,3} \mathrm{NN}$ Than, ${ }^{1,4} \mathrm{M}$ Nizamuddin, 1,3 D Adams, ${ }^{1,3} \mathrm{YH}$ Oo. ${ }^{1}$ Queen Elizabeth Hospital, Birmingham, UK; ${ }^{2}$ Gastroenterology, Walsall Healthcare NHS Trust, Walsall; ${ }^{3}$ Centre for Liver Research and NIHR BRU, University of Birmingham, UK; ${ }^{4}$ Gastroenterology, Russels Hall Hospital, Birmingham, UK

10.1136/gutinl-2014-307263.197

Introduction Autoimmune hepatitis (AIH) is due to breakdown in immunological self-tolerance. Sustained remission in AIH is crucial to prevent the progression to end stage liver disease. ${ }^{1}$ Around $9 \%$ of the patients are refractory/intolerant to the standard therapy with prednisolone (Pred) \pm azathioprine (AZA). High levels of immunoglobulin are typical of AIH and plasma cells are frequently observed in liver histology. Rituximab is an anti-CD20 monoclonal antibody that depletes B-cells and has been used to treat other autoimmune conditions such as systemic lupus erythematosus. However, little has been reported on the role of B cells depletion and its outcome in AIH.

The aim of the study was to evaluate the safety and efficacy of rituximab in the treatment of refractory $\mathrm{AIH}$.

Methods A retrospective case note review of well-defined and biopsy proven type-1 AIH (simplified scoring >6). 5 patients out of 200 who were intolerant/refractory to standard therapy were given Rituximab and the responses were followed up for 72 weeks.

Efficacy was measured by biochemical and immunological parameters (bilirubin, AST, ALT and Immunoglobulin every 12 weeks. The dose of Prednisolone as well as UKELD/MELD score pre and post treatment was also evaluated.

Results All 5 patients were female and mean age was 45 (range $35-66$ yrs). The rituximab dose used was $1000 \mathrm{mg}$ and the total number of doses received varied between 2 and 4 (Mean 3.2). Three patients had other concomitant autoimmune conditions (endocrine, rheumatological and renal related autoimmune diseases). The mean dose of prednisolone used pre-rituximab was $19 \mathrm{mg}( \pm$ SD 12.57$)$ and this was reduced to $12.5 \mathrm{mg}$ ( \pm SD 5.0) post treatment (statistically not significant $=$ NS). There was a slight improvement of IgG pre and post Rituximab treatment (NS), with no improvement in UKELD score. There was an improvement in biochemical profile but this was not statistically significant throughout the observation period. All five patients were alive and rituximab was well tolerated without any serious adverse events.

Conclusion Rituximab is well-tolerated and safe to use in resistant AIH. It can cause some biochemical and immunological improvement. Current evidence for its use in AIH patients is not well proven. The study numbers are too small to detect the actual outcome of the therapy. A multicenter larger cohort prospective study with longitudinal immunological, biochemical and histological profile assessment is warranted to assess its efficacy in resistant $\mathrm{AIH}$ patients.

\section{REFERENCE}

1 Czaja AJ. Current and future treatments of AlH. Expert Rev Gastroenterology Hepatol 2009:3: 269-91

Disclosure of Interest None Declared.

\section{PTU-124 AN EXTERNAL VALIDATION OF THE HEPATOMA ARTERIAL-EMBOLISATION PROGNOSIS (HAP) SCORE: THE LIVERPOOL EXPERIENCE}

${ }^{1} O$ Noorullah*, ${ }^{2} V P$ Lekharaju, ${ }^{3} \mathrm{UU}$ Din, ${ }^{3} \mathrm{~J}$ Klcova, ${ }^{4} \mathrm{~T}$ Cross, ${ }^{5} \mathrm{~J}$ Evans, ${ }^{1} \mathrm{R}$ Sturgess, ${ }^{6} \mathrm{D}$ Palmer, ${ }^{3} \mathrm{E} \mathrm{O}^{\prime} \mathrm{Grady},{ }^{1} \mathrm{~N}$ Stern. ${ }^{1}$ Digestive Diseases Unit, Liverpool, UK; ${ }^{2}$ Aintree University Hospital, Liverpool, UK; ${ }^{3}$ Department of Radiology, Aintree University Hospital, UK; ${ }^{4}$ Department of Gastroenterology, Royal Liverpool University Hospital; ${ }^{5}$ Department of Radiology, Royal Liverpool University Hospital; ${ }^{6}$ University of Liverpool, Liverpool, UK

\subsection{6/gutjnl-2014-307263.198}

Introduction Most Hepatocellular Carcinomas (HCCs) have palliative treatment. Trans-arterial embolisation (TAE) or chemoembolisation (TACE) are used with variable results. The HAP score was recently described to determine patients likely to benefit from TAE or TACE. We report our experience with TAE and TACE to assess whether the HAP score was valid for our cohort of patients.

Methods Retrospective review of cases given TAE or TACE in Liverpool, UK (2006-2013). HAP score [1 point each for albu$\min <36 \mathrm{~g} / \mathrm{dl}$, AFP $>400 \mathrm{ng} / \mathrm{ml}$, Bilirubin $>17 \mu \mathrm{mol} / \mathrm{l}$, tumour diameter $>7 \mathrm{~cm}$. HAP A $=0$ points, $\mathrm{B}=1, \mathrm{C}=2, \mathrm{D}$ $>2]$. Outcome recorded according to HAP score.

Results 137 patients identified having received TAE/TACE with full data to complete HAP score. Mean age 69; 116 (84.7\%) male. 78.8\% AUH, 21.2\% RLUH. HAP score A: 44 (32.1\%); B: 40 (29.2\%); C: 32 (23.4\%); D: 21 (15.3\%). Overall median survival 492 days (16 months). Median survival by HAP score, A: 492 days; B: 839 days; C 478 days; D 309 days. Log rank p < 0.001. Survival at 1 year: A $62.8 \%$; B 75\%; C59.4\%, D 28.6\%. Survival at 2 years: A $29.5 \%$, B $52.5 \%$, C $37.5 \%$, D $14.3 \%$. HAP D patients had lower median survival (309 vs. 563 days; $p$ $<0.001$ ) and 1 and 2 year survival (28.6 vs. $65.5 \%$; $\mathrm{p}=0.001$ and 14.3 vs $39.7 \% ; \mathrm{p}=0.021$ ).

Conclusion Patients with HAP score D due TACE have a relatively poor outcome in this external validation group. This should be considered when planning treatment or further trials.

\section{REFERENCE}

Kadalayil et al. Annals of Oncology 2013

Disclosure of Interest None Declared.

\section{PTU-125 BIOCHEMICAL PATTERNS OF PRESENTATION IN PRIMARY SCLEROSING CHOLANGITIS: YOUNGER AGE AT ONSET IS ASSOCIATED WITH A LOWER ALPIAST RATIO}

${ }^{1}$ PJ Trivedi ${ }^{*},{ }^{1} J$ Robinson, ${ }^{1} \mathrm{~T}$ Wright, ${ }^{1,2} \mathrm{~T}$ Bruns, ${ }^{1} \mathrm{~K}-\mathrm{K}$ Li, ${ }^{1} \mathrm{H}$ Shah, ${ }^{1} \mathrm{D}$ Adams, ${ }^{3} \mathrm{~J}$ Ferguson, ${ }^{1} \mathrm{G}$ Hirschfield. ${ }^{1}$ NIHR Biomedical Research Unit and Centre for Liver Research, University of Birmingham, Birmingham, UK; ${ }^{2}$ Department of Internal Medicine IV, Jena University Hospital, Friedrich Schiller University Jena, Jena, Germany; ${ }^{3}$ Liver Unit, University Hospitals Birmingham, Queen Elizabeth Hospital, Birmingham, UK

\subsection{6/gutjpl-2014-307263.199}

Introduction Autoimmune sclerosing cholangitis is the paediatric term applied to children presenting with features of autoimmune hepatitis and sclerosing cholangitis. We hypothesised that if this inflammatory phenotype was a continuum, young adults with primary sclerosing cholangitis (PSC) would also have a more inflammatory presentation.

Methods We undertook a retrospective case-note review of our patients with an established diagnosis of PSC presenting between 2003-2013 ( $\mathrm{n}=116)$. Clinical characteristics and laboratory 